\title{
Comparativo de la capacidad del desarrollo embrionario de Bos indicus y Bos taurus en embriones producidos in vitro
}

\section{Comparison of the embryonic development capacity of Bos indicus and Bos taurus in embryos produced in vitro}

\author{
iD 'Giovana Bustamante S. (iD 'Erika Alayo A. (iD) 'Maricelia Alvarado B. \\ iD 'Iván Mesia L. ID 'Julia Ramírez S.
}

Laboratorio Biotecnológico Sembryo - Láctea S.A. La Libertad - Perú

Universidad Nacional de Trujillo- Facultad de Ciencias Agropecuarias, Trujillo. La Libertad²

\section{Resumen}

La aplicación de la biotecnología permite aumentar la eficiencia reproductiva y el progreso genético del ganado vacuno. La presente investigación tuvo como objetivo comparar la capacidad de desarrollo de embriones producidos in vitro provenientes de Bos indicus y Bos taurus. Se evaluaron ovocitos colectados en los mismos periodos y épocas del año de estas subespecies; las donadoras estuvieron bajo las mismas condiciones de manejo, tanto sanitarias como nutricionales y sin estimulo hormonal. Se aplicó la prueba de Fisher para comparar el porcentaje de ovocitos viables y el porcentaje de embriones producidos por ambas subespecies y prueba t-student con nivel de significancia $p:<0.05$. Hubo diferencias estadísticamente significativas en la producción de embriones (28.6 \% vs $38.6 \%$ ) para Bos taurus y Bos indicus, respectivamente. Se concluye a partir de los resultados obtenidos, que la subespecie Bos indicus tienen mayor capacidad de producción de embriones en comparación con la subespecie Bos Taurus. Palabras clave: Vacuno, biotecnología, embriones, Bos indicus, Bos taurus.

Recibido: Junio 2020

Aceptado: Octubre 2020

\section{Abstract}

The application of biotechnology allows increasing the reproductive efficiency and genetic progress of cattle. The present research aimed to compare the development capacity of embryos produced in vitro from Bos indicus and Bos Taurus. Oocytes collected in the same periods and times of the year from these subspecies were evaluated; the donors were under the same management conditions, both sanitary and nutritional and without hormonal stimulation. Fisher's test was applied to compare the percentage of viable oocytes and the percentage of embryos produced by both subspecies and the t-student test with a significance level of $\mathrm{p}:<0.05$. There were statistically significant differences in embryo produc- 
tion (28.6\% vs 38.6\%) for Bos taurus and Bos indicus, respectively. It was concluded from the results obtained, that the subspecies Bos indicus have a greater capacity for embryo production compared to the subspecies Bos Taurus.

Keywords: Cattle, biotechnology, embryos, Bos indicus, Bos taurus.

\section{INTRODUCCIÓN}

El ciclo reproductivo natural en el bovino conduce al nacimiento de una cría por año en el mejor de los casos. Para mejorar la eficiencia reproductiva de animales de alto mérito genético se utilizan técnicas de reproducción asistida (Ploudre et al, 2012). Este procedimiento, permite multiplicar la descendencia de animales de alta calidad genética, acortando simultáneamente el intervalo generacional y facilitando diferentes actividades de mejoramiento genético, como la evaluación de la progenie y la comparación entre grupos de animales (Satori et al, 2002).

La biotecnología ha experimentado un gran auge en las últimas décadas y ha dotado a la ciencia de nuevas herramientas capaces de manipular y modificar el genoma de los seres vivos más evolucionados: los mamíferos. El desarrollo de nuevas biotecnologías para producir animales transgénicos, o para la multiplicación in vitro de líneas de animales genéticamente superiores, se basa en el avance de las técnicas de fertilización in vitro (FIV) y en el cultivo de embriones.

Un objetivo valioso del desarrollo de la biotecnología, es la producción in vitro de embriones bovinos, como base para otras biotecnologías, que aseguren una alta tasa de preñez cuando son transferidos a hembras receptoras, obteniéndose el nacimiento de crías saludables (Hansen., 2006).

La fecundación in vitro (FIV) de ovocitos bovinos es una técnica beneficiosa que permite obtener embriones, lo que representa grandes ventajas en reproducción animal garantizando un elevado número de embriones en el mismo estadio de desarrollo, clonación mediante transferencia nuclear y producción de animales transgénicos (Gadea et al., 1998), biotecnologías que permiten el mejoramiento genético necesario, para vencer las limitaciones impuestas por las condiciones ambientales (Gutiérrez et al., 2017). Además, las técnicas de FIV son la única opción disponible para producir crías de hembras valiosas, que por causas no genéticas son estériles y por lo tanto son eliminadas de los sistemas productivos (Ratto et a.l, 1999). Esta técnica tiene muchas posibilidades; puede ser usada en vacas cíclicas, no cíclicas, durante el primer tercio de la gestación y en las que no responden a estímulos hormonales; también, en animales con desórdenes reproductivos de origen no genético (Galli et al., 2001), y en terneras y novillas pre púberes a partir del 60-80 mes de edad (Taneja et al., 2000).

Cada vez es más evidente la importancia del componente racial sobre los eventos fisiológicos del embrión y los gametos que le dan origen y dada la importancia de la ganadería en el país, es importante caracterizar la influencia de dicho componente sobre la capacidad de desarrollo embrionario en bovinos. La realización de estudios donde se compare la capacidad de desarrollo embrionario entre las subespecies $B$. taurus y $B$. indicus, permitirá contribuir a fortalecer los conocimientos relacionados con las diferencias biológicas existentes entre estas dos especies (Báez et al., 2010).

El ganado $B$. taurus es muy sensible a las condiciones climáticas, experimentando grados variables de infertilidad. Los animales con mayor herencia cebuina (B. indicus); además, de ser menos exigentes en alimentación debido a su menor producción lechera, poseen características anatómicas y funcionales que los hacen más aptos para resistir las condiciones ambientales adversas, mayor resistencia 
a enfermedades por lo cual mantienen tasas de fertilidad más elevadas a lo largo del año (Barros et al., 2006). La subespecie B. indicus (ganado cebú) es predominante en las regiones tropicales, debido a su mejor tolerancia al estrés térmico y la resistencia a los parásitos que las razas europeas (B. taurus), las cuales son predominantes en climas templados (Dubuc et al., 1984). En comparación con las razas europeas, el ganado cebú experimenta una menor reducción en el consumo de alimento, en la tasa de crecimiento, la producción de leche y la función reproductiva, en respuesta al estrés térmico (Barros et al., 2006).

En los últimos años se han desarrollado diversos programas de producción in vitro de embriones bovinos y son numerosos los profesionales que están dedicados a esta biotecnología. Estos programas obedecen en gran medida, de las razas que se trabajen, tanto en Bos taurus como en Bos indicus, sin embargo, dependiendo de las condiciones ambientales, varían. Por consiguiente, es importante registrar los detalles de trabajos locales, que sirvan como soporte técnico para el personal que se desempeña en esta actividad (van Wagtendonk.,, 2006).

Se espera que el conocimiento generado de la selección de una de las subespecies predominantes, $B$. taurus o $B$. indicus, sea utilizado como fuente de gametos femeninos, que muestren la mayor capacidad de producción embrionaria in vitro, para la FIV; esto permitirá mejorar la eficiencia de la PIV de embriones bovinos. El presente estudio expone el resultado del trabajo realizado en el laboratorio biotecnológico SEMBRYO en LACTEA S.A, ubicado en el departamento de La Libertad Perú, en el cual se realizó una evaluación de la capacidad de desarrollo embrionario producidos in vitro a partir de ovocitos provenientes de subespecies de vacas Bos taurus, vs Bos indicus, ambas especies de hembras fueron manejadas bajo las mismas condiciones medio ambientales y usando el mismo protocolo para la producción de los embriones in vitro.
El objetivo de este estudio fue presentar datos de producción de embriones in vitro a gran escala, basado en el trabajo de campo y el laboratorio SEMBRYO, con el fin de analizar la capacidad de desarrollo embrionario in vitro y por medio de los promedios de producción, comparar los resultados entre embriones producidos a partir de subespecies de vacas Bos taurus y Bos indicus sobre la producción de blastocistos.

\section{MATERIALES Y MÉTODOS Selección de donadoras de ovocitos.}

La aspiración de las donadoras se ejecutó durante un periodo de seis meses comprendido entre el mes de marzo a agosto del 2018, con sesiones de aspiración folicular de dos veces por semana. Como donadoras se seleccionaron hembras de las subespecies Bos indicus y Bos taurus con una edad promedio entre los 2 a 4 años, con buena condición corporal, con historia sanitaria, productiva y reproductiva normal; dichas donadoras fueron alimentadas con forraje de broza y chala durante el periodo que fueron sometidas a aspiración. Para lo cual, en campo las vacas fueron colocadas en un brete para realizar la inspección ginecológica y de esta manera determinar si la vaca estaba limpia. Cabe recalcar que las donadoras no fueron sometidas a protocolos de superovulación hormonal.

Para la recolección de ovocitos se utilizó la técnica de OPU (Ovum Pick Up) en la cual en cada sesión se utilizó un ecosonógrafo conectado a un transductor, usándose también una bomba de aspiración, trabajándose con una presión de vacío que osciló entre 15 a $16 \mathrm{~cm}^{3} / \mathrm{min}$. Se ubicó por palpación rectal uno de los ovarios y se procedió a identificar en la pantalla del monitor los folículos. Se orientó el ovario para visualizar el folículo a aspirar y se realizó una punción del folículo previsto, aspirando el contenido del mismo, continuando sucesivamente en todos los folículos de ese ovario. Se procedió de manera idéntica con el otro ovario.

\section{Búsqueda y selección de ovocitos}

En el laboratorio el día de la colecta se proce- 
dió a preparar el medio de aspiración y medio de enjuague a base de PBS + antibiótico + heparina + BSA, los cuales se enviaron a las instalaciones donde se realizó la colecta del ovocitos en tubos con los datos necesarios, identificando el código de la vaca, para poder de esta manera diferenciarlas entre las subespecies Bos taurus y Bos indicus. Una vez realizada la colecta, los tubos fueron transportados al laboratorio a una temperatura de $38^{\circ} \mathrm{C}$, donde el contenido de los tubos fue pasado a través de un filtro y lavado con medio de enjuague, y luego depositarlos en placas de 100 mm y realizar la observación bajo estereoscopio para su respectiva búsqueda, selección y clasificación.

\section{Maduración de ovocitos}

Para la maduración se utilizó medio B-199 suplementado con hormonas como LH, FSH, estradiol, FCS (Suero fetal bovino), factor de crecimiento epidermal. Los complejos cumulus- ovocito fueron cultivados en grupos de 10, en microgotas de medio y mantenidos en un incubador de $\mathrm{CO}_{2}$ durante 24 horas a $38,5^{\circ} \mathrm{C}$ en una atmósfera con $5 \% \mathrm{CO}_{2}$ en aire saturado de humedad (Figura 1)

\section{Capacitación espermática}

Para llevar a cabo la FIV se utilizó semen congelado de un toro Brahman puro (B. indicus) para las vacas de raza pura Bos indicus y un toro B. taurus puro para las vacas de raza pura Holstein previamente probada la fertilidad de dichos toros. La capacitación espermática se realizó con la técnica de gradiente de PERCOLL, el semen a trabajar se depositó sobre un tubo cónico de $15 \mathrm{~mL}$ que contenía $1 \mathrm{~mL}$ de Percoll 45 y $1 \mathrm{~mL}$ de Percoll de 90, se llevó a la centrifuga a 3000 rpm por 30 minutos. Se retiró cuidadosamente el pellet y se homogenizó con $1 \mathrm{ml}$ de Talp 1x, se centrifugó por segunda vez a 1500 rpm por 20 min. Se retiró el sobrenadante y este se homogenizó con medio Talp IVF. Se calculó la concentración y motilidad ajustando la concentración a 1.5 millones de espermatozoides/mL.

\section{Fecundación in vitro}

Una vez transcurrido el tiempo de maduración, los COC (Complejo Ovocito Células) previamente se denudaron parcialmente y se trasladaron en grupos de 10 ovocitos a microgotas conteniendo Talp IVF, posteriormente se procedió a fertilizar con la mezcla de la suspensión de semen a cada gota conteniendo los ovocitos. Luego, se colocaron en la incubadora durante 18 a 24 horas a $38,5^{\circ} \mathrm{C}$ en una atmósfera saturada de humedad, bajo $5 \% \mathrm{CO}_{2}$.

\section{Cultivo embrionario}

Aproximadamente 18 horas post inseminación, se denudaron los ovocitos casi completamente por pipeteo en las mismas gotas de medio de fecundación y se lavaron medio de lavado antes de transferirlos a microgotas de medio de cultivo temprano cubiertas. Las placas de cultivo fueron incubadas a $38,5^{\circ} \mathrm{C}$ en incubadora de mezcla de gases $\left(5 \% \mathrm{CO}_{2}, 88\right.$ $\%$ de Nitrógeno, $7 \%$ de Oxígeno a > $85 \%$ de humedad). En el día 4 post cultivo se realizó el cultivo tardío, realizando la renovación de medio de cultivo CIV y la evaluación de división embrionaria; así mismo, se retiró el restante de las células del cúmulus. Posteriormente para el día 7 se obtuvieron los embriones en el estado de blastocisto y/o blastocisto expandido, como se muestra en la Figura 2.

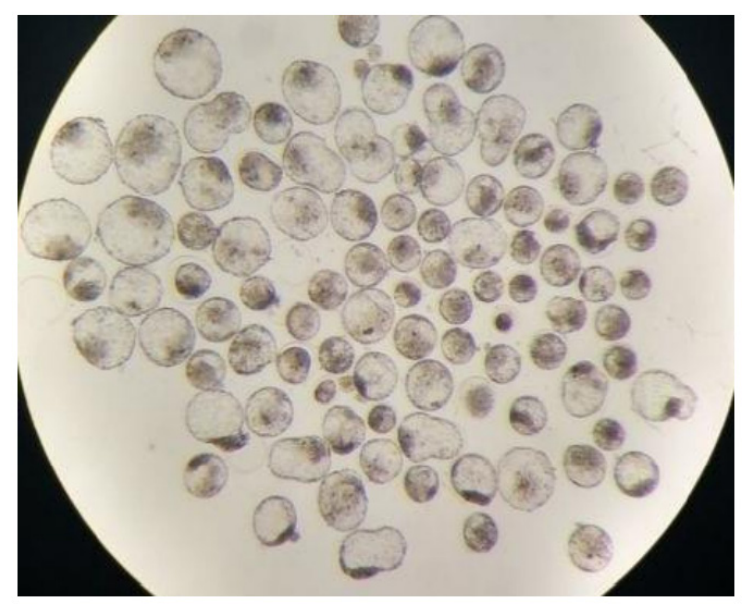

Figura 1. Ovocitos post maduración en el laboratorio Sembryo - Láctea S.A 


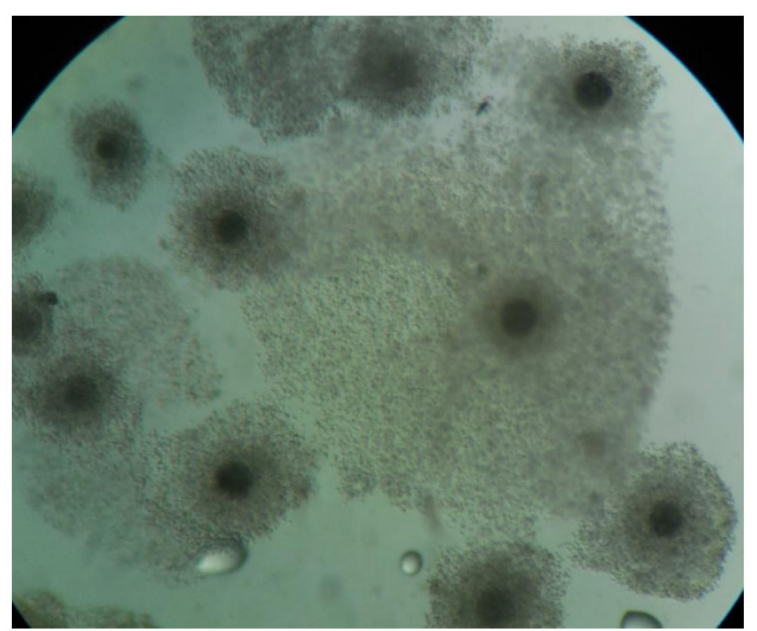

Figura 2. Blastocistos obtenidos al día 7 en el laboratorio Sembryo - Láctea S.A

\section{RESULTADOS Y DISCUSIÓN}

Se colectaron, un total de 2366 ovocitos en el periodo comprendido entre marzo del 2018 y agosto del 2018, de los cuales 1424 ovocitos pertenecieron a la subespecie Bos taurus, y 1,442 ovocitos de la subespecie Bos indicus, los resultados se resumen en la Tabla 1. Del total de ovocitos colectados, fueron a maduración 1,310 para la subespecie Bos taurus y 1,282 para la subespecie Bos indicus respectivamente, de estos últimos pasadas 24 horas solo fueron fertilizados 1,248 para la subespecie Bos taurus y
1,130 para Bos indicus respectivamente.

Los análisis de los datos obtenidos se resumen en la Tabla 2, observándose que no hubo diferencias estadísticamente significativas entre las colectas de las subespecies Bos taurus y Bos indicus (Tabla 1). Sin embargo, se encontró diferencia estadísticamente significativa $(p<0.05)$ entre la producción de blastocistos (28.6 \% vs $36.6 \%$ ) entre las subespecies Bos taurus y Bos indicus, respectivamente (Tabla 2).

\section{Tabla 1}

Número total de ovocitos producidos por Bos taurus y Bos indicus.

\begin{tabular}{cc}
\hline & $\mathbf{N}^{\circ}$ ovocitos colectados \\
\hline BUBESPECIE & $1424^{\mathrm{a}}$ \\
Bos indicus & $1442^{\mathrm{a}}$ \\
\hline
\end{tabular}

Letras iguales significa que no existe diferencia estadística significativa $(\mathrm{p}>0.05)$

\section{Tabla 2}

Porcentaje total de ovocitos fertilizados y de blastocistos producidos por Bos taurus y Bos indicus.

\begin{tabular}{lcccccc}
\hline SUBESPECIE & $\begin{array}{c}\text { Ovocitos } \\
\text { encontrados } \\
\text { (n) }\end{array}$ & $\begin{array}{c}\text { Ovocitos } \\
\text { madurados } \\
\text { (n) }\end{array}$ & $\begin{array}{c}\text { Ovocitos } \\
\text { fertilizados } \\
\text { (n) }\end{array}$ & $\begin{array}{c}\text { Ovocitos } \\
\text { fertilizados } \\
(\%)\end{array}$ & $\begin{array}{c}\text { Blastocistos } \\
\text { producidos } \\
\text { (n) }\end{array}$ & $\begin{array}{c}\text { Blastocistos } \\
\text { producidos } \\
\text { (\%) }\end{array}$ \\
\hline Bos taurus & 1424 & 1310 & 1248 & $87.6404494^{\mathrm{a}}$ & 357 & $28.6057692^{\mathrm{a}}$ \\
Bos indicus & 1442 & 1282 & 1130 & $78.3633842^{\mathrm{a}}$ & 414 & $36.6371681^{\mathrm{b}}$ \\
\hline
\end{tabular}

Letras diferentes en las casillas, corresponden a que existe diferencia estadísticamente significativa $(\mathrm{p}<0.05)$. Letras iguales en las casillas corresponden, que no hay diferencias esta estadísticamente significativas ( $>>0.05)$. 
Los resultados obtenidos concuerdan con los reportados por Báez et al., (2010), en los cuales se mostró que el ganado con predominancia fenotípica Bos indicus presentó mejores tasas de desarrollo embrionario, debido a que sus ovocitos fueron más competentes al tener genes termo tolerantes, con capacidad para resistir las condiciones ambientales del trópico, y podían llegar a desarrollarse estos ovocitos luego de la fecundación en mayor porcentaje de embriones que los del ganado Bos taurus (Báez et al., 2010).

Resultados contrarios se obtuvieron en estudios reportados por Bryant (2007), donde hubo mejores tasas de desarrollo embrionario en Bos taurus que en Bos indicus, exhibiendo que los ovocitos de la raza Brahman (Bos indicus) presentan una mayor concentración de lípidos comparado con las razas europeas (Bos taurus), lo que resulta en una menor respuesta a la fertilización in vitro, por consiguiente, menores tasas de preñez (Bryant., 2007). Este mismo autor, reportó resultados de la evaluación de los niveles séricos de colesterol y triglicéridos en las hembras donadoras bajo las mismas condiciones dietarías, encontrándose un nivel circulante más elevado de colesterol y de triglicéridos en la raza Brahman (Bos indicus) comparada con las razas inglesas (Bos taurus) (Camargo et al., 2007), lo que afectan directamente la influencia de la cantidad de lípidos encontrados en los ovocitos de ambas subespecies (Bryant, 2007); esto podría respaldar la menor tasa de producción de embriones in vitro, del ganado Bos indicus vs Bos taurus.

Los resultados de este estudio son similares a los reportados por Chávez et al, 2010 el cual encontró que, en vacas Holstein (Bos taurus), el estrés calórico parece reducir la competencia ovocitaria y las tasas de fecundación, reduciendo el desarrollo del embrión contribuyendo a una mala fertilidad durante los meses de verano; a diferencia de ganado cebú (Bos indicus) que está bien adaptado a los ambientes tropicales, evidenciando una máxima to- lerancia al calor, mostrando mejor rendimiento reproductivo que Bos taurus en regiones tropicales y subtropicales, concluyendo que en ambientes tropicales el ganado Bos indicus presenta mejores índices de reproducción que el ganado Bos taurus.

Estudios recientes, han señalado que, el estrés calórico ejerce un efecto nocivo retrasado sobre el desarrollo folicular, los niveles de progesterona y sobre la competencia ovocitaria en vacas del género Bos indicus, a diferencia del Bos taurus, donde el estrés calórico causa un inmediato deterioro sobre el desarrollo folicular (Sun., 2003). No se conoce concretamente el mecanismo por el cual el estrés calórico puede afectar a los folículos y a los ovocitos, pero, se ha descrito que se produce un daño en la comunicación intercelular entre las células de la granulosa, del cúmulus y el ovocito. Se afecta la competencia del ovocito para ser fecundado (Al Katanani., 2002), la viabilidad de las células de la granulosa y de la teca interna, y se producen cambios en la esteroidogénesis (Roth et al., 2001). Por tanto, algunos folículos pudiesen ser afectados aún antes de su reclutamiento lo que se traduce en la prolongación de los efectos del estrés térmico aún en los meses con condiciones más confortables (Lozano., 2005).

Visintin et al., (2002), señaló que existen diferencias ultraestructurales importantes, si se comparan embriones de Nelore (Bos taurus indicus) y Holstein Freisian (Bos taurus taurus) y que por estas diferencias existe la posibilidad de una mejor respuesta en la obtención de embriones in vitro. Sin embargo, existen otros estudios en los cuales no se encontraron diferencia de embriones producidos in vitro, sugiriendo que el porcentaje de fertilización in vitro no es afectado por la raza o el estado fisiológico (Leroy et al, 2005). Los resultados encontrados en el presente estudio evidencian que, si existe una influencia de la subespecie de la donadora en la cantidad de embriones obtenidos en la fertilización in vitro; no obstante, existen otros factores aso- 
ciados importantes que se deben tener en cuenta tales como: etapa de producción de la donadora (si están en producción láctea o están secas), la temperatura del medio ambiente o estación del año (Tobón., 2004).

\section{CONCLUSIONES}

- No hubo diferencia significativa entre los ovocitos recuperados de las subespecies Bos indicus y Bos taurus.

- La producción de blastocisto fue mejor en la subespecie Bos indicus comparado con los blastocistos producidos por Bos taurus.

- La subespecie Bos indicus mostró tener mayor capacidad de producción de embriones en comparación con la subespecie Bos taurus.

\section{REFERENCIAS BIBLIOGRÁFICAS}

Al Katanani, Y.; Paula-Lopes, F.; Hansen, P. (2002). Effect of season and exposure to heat stress on oocyte competente in Holstein cows. Journal of Dairy Science. 85: 390-396.

Báez, F.; Chávez, A.; Hernandez, H.; Villamediana, P. (2010). Evaluación de la capacidad de desarrollo in vitro de ovocitos bovinos provenientes de vacas con predominancia fenotípica Bos taurus y Bos indicus. Revista Científica Maracaibo. Venezuela. 20(3).

Barros, C.; Pegorer, M.; Moraes, J.; Eberhardt, B.; Monteiro, F. (2006). Importance of sperm genotype (indicus versus taurus) for fertility and embryonic development at elevated temperatures. Theriogenology. 65: 210-218.

Bryant, BC. (2007). Intracellular lipids in Bos indicus and Bos taurus oocytes. A post-grade thesis. B.S., Texas A\&M Lousiana University. College Station, pp. 112-119.

Camargo, L.; Viana, J.; Ramos, A.; Serapiao, R.; De Sa, W.; Ferreira, A.; Guimaraes, M.; Vale-Filho, V. (2007). Develomntal competence and expression of the Hsp 70.1 gene in oocytes obtained from Bos indicus and Bos taurus dairy cows in a tropical environment. Theriogenology. 68: 626-632.

Chávez, A.; Báez, F.; Hernández, H.; Villamediana, P. (2010). Evaluación de la capacidad de desarrollo in vitro de ovocitos bovinos provenientes de vacas con predominancias fenotípicas de las especies Bos taurus y Bos indicus. Revista Científica de Veterinaria. 20(3): 259-267.

Dubuc, M (1984). Animales Tropicales. Zebuinos y Azebuados. Espesantes S.R.L (Ed). Caracas-Venezuela. 3era Ed, pp. 21-25.

Gadea, J.; Ruiz, P.S.; Coy, A.; Poto, A.; Peinado, B.; Romar, R.; Campos, l.; Zubillaga, O. (1998). Fecundación in vitro con semen congelado en la especie porcina. Archivos de Zootecnia (47): 299-304.

Galli, C.; Crotti, G.; Notari, C.; Turini, P.; Duchi, R.; Lazzari, G. (2001). Embryo production by ovum pick up from live donors. Theriogenology. 55: 1341-1357.

Gutiérrez, C.; Cifuentes, E.; Pérez, V; Romero, L.; Martínez H, N.; González T, M. (2017). Transferencia de embriones fecundados in vitro en ganado bovino de doble propósito. Revista MVZ Córdoba; 6(1): 52-57.

Hansen, P. (2006). Realizing the promise of IVF in cattle an overview. Theriogenology (65):119-125.

Leroy, J; Opsomer, G,; De Vliegher, S,; Vanholder, $T_{\text {; }}$ Goossens, L, et al. (2005). Comparison of embryo quality in high-yeldin dairy cows, in diary heifers and in beef cows. Theriogenology; 64 (9): 2022-2036.

Lozano, R. R.; Vásquez, C. G.; González-Padilla, E. (2005). Effect of heat stress and its interaction with other management and productive variables on pregnancy rate in dairy cows in Aguascalientes, México. Veterinaria México. 36 (3): 245-260.

Plourde, D.; Vigneault, C.; Laflamme, I.; Blondin, P.; Robert, C. (2012). Cellular and molecular 
characterization of the impact of laboratory setup on bovine in vitro embryo production. Theriogenology, doi: 10.1016/j.theriogenology. 2011.12.021: 1767-1778.

Ratto, M.; Berland, M.; Wolter, M.; Matamoros.; R. (1999). Bovine embryo development produced by in vitro fertilization cultured with oviductal cell or conditioned medium and transfer to recipients. Archivos de Medicina Veterinaria. 31 (1):89-96.

Roth, Z.; Meidan, R.; Shaham-Albalancy, A.; Braw Tal, R.; Wolfenson, D. (2001). Delayed effect of heat stress on steroid production in medium sized and preovulatory bovine follicles. Reproduction. 121: 745-751.

Satori, R.; Sartor, B.; Guenther, J.; Parrish, J.; Wilthbank, M. (2002). Fertilization and early embryonic development in heifers and lactating cows in summer and lactating and dry cows in winter. Journal of Dairy Science; 85 (11): 2803-2812.

Sun, QY. (2003). Cellular and molecular mechanisms leading to cortical reaction and polyspermy block in mammalian eggs. Microscience Research Technology. 61:342-348.

Taneja, M.; Bols, PE.; Van de Velde, A.; Ju, JC.; Schreiber, D.; Tripp, MW. (2000). Developmental competence of juvenile calf oocytes in vitro and in vivo: influence of donor animal variation and repeated gonadotropin stimulation. Biology of Reproduction. 62: 206-213.

Tobón J. (2004). Repoblamiento ganadero. Editorial Marin Vieco Ltda.

Van Wagtendonk de Leeuw, AM. (2006). Ovum Pick-Up and in-vitro Production in the bovine alter several generations: a 2005 status. Theriogenology; 65 (5): 914-925.

Visintin, JA ; Martinus, JF; Bevilacgua, EM ; MelIo, MR,; Nicacio, AC; A ssumpcao, ME. (2002). Cryopreservation of Bos taurus vs. Bos indicus embryos: are they really different. Theriogenology; 57 (1): 345-359.

\section{CORRESPONDENCIA:}

Dra. Julia M. Ramírez Sánchez jramirez@unitru.edu.pe 